\title{
Resequencing analysis of five Mendelian genes and the top genes from genome- wide association studies in Parkinson's Disease
}

\author{
Bruno A. Benitez ${ }^{1 *}$, Albert A. Davis², Sheng Chih Jin ${ }^{3}$, Laura Ibanez ${ }^{3}$, Sara Ortega-Cubero ${ }^{4,5}$, Pau Pastor ${ }^{5,6}$, \\ Jiyoon Choi $^{3}$, Breanna Cooper ${ }^{3}$, Joel S. Perlmutter ${ }^{2,7,8}$ and Carlos Cruchaga ${ }^{3,8}$
}

\begin{abstract}
Background: Most sequencing studies in Parkinson's disease (PD) have focused on either a particular gene, primarily in familial and early onset PD samples, or on screening single variants in sporadic PD cases. To date, there is no systematic study that sequences the most common PD causing genes with Mendelian inheritance [a-synuclein (SNCA), leucine-rich repeat kinase 2 (LRRK2), PARKIN, PTEN-induced putative kinase 1 (PINK1) and DJ-1 (Daisuke-Junko-1)] and susceptibility genes [glucocerebrosidase beta acid (GBA) and microtubule-associated protein tau (MAPT)] identified through genome-wide association studies (GWAS) in a European-American case-control sample ( $n=815)$.

Results: Disease-causing variants in the SNCA, LRRK2 and PARK2 genes were found in $2 \%$ of PD patients. The LRRK2, p.G2019S mutation was found in $0.6 \%$ of sporadic PD and $4.8 \%$ of familial PD cases. Gene-based analysis suggests that additional variants in the LRRK2 gene also contribute to PD risk. The SNCA duplication was found in $0.8 \%$ of familial PD patients. Novel variants were found in $0.8 \%$ of PD cases and $0.6 \%$ of controls. Heterozygous Gaucher disease-causing mutations in the GBA gene were found in $7.1 \%$ of PD patients. Here, we established that the GBA variant (p.T408M) is associated with PD risk and age at onset. Additionally, gene-based and single-variant analyses demostrated that GBA gene variants (p.L483P, p.R83C, p.N409S, p.H294Q and p.E365K) increase PD risk.

Conclusions: Our data suggest that the impact of additional untested coding variants in the GBA and LRRK2 genes is higher than previously estimated. Our data also provide compelling evidence of the existence of additional untested variants in the primary Mendelian and PD GWAS genes that contribute to the genetic etiology of sporadic PD.
\end{abstract}

Keywords: Parkinson's, Association study, SNCA, LRRK2, PARKIN, PINK1, DJ-1, MAPT, GBA rare variants, gene-based analysis

\section{Background}

$\mathrm{PD}$ is the second most common neurodegenerative disorder after Alzheimer's disease (AD) [1]. By the year 2030, the prevalence of PD is projected to be between 8.7 and 9.3 million [1]. Genetic studies in PD have provided valuable insights into the underlying pathogenic mechanisms [2], leading to the development of animal models for investigation of disease mechanisms and identification of novel therapeutic targets [3]. Initial

\footnotetext{
* Correspondence: babenitez@wustl.edu

'Department of Internal Medicine, School of Medicine, Washington University, 8007660 South Euclid Avenue, St. Louis, MO 63110, USA Full list of author information is available at the end of the article
}

studies of multiplex families with PD found concordance rates of $75 \%$ in monozygotic twins, $22 \%$ in dizygotic twins [5], and an increased relative risk of PD of 2.9 (95 $\%$ CI 2.2-3.8) for those with an affected first-degree relative [6]. These findings indicate that the genetic etiology of PD does not fit a simple genetic model [5]. GWAS of PD have identified variants at 20 loci influencing PD risk [2, 4, 7-9], with population-specific differences $[10,11]$. The currently identified genetic factors explain only $6-7 \%$ of the phenotypic variability associated with PD [12], and the most prevalent GWA signals account for only 3-5\% of PD genetic variance in individuals of European ancestry [12]. These results 
provide unequivocal, compelling evidence for the existence of undiscovered genetic factors that contribute to the etiology of PD. Both candidate gene association studies and GWAS repeatedly validate that the most statistically significant signals associated with $\mathrm{PD}$ are common variants located close to SNCA, LRRK2, MAPT genes and low frequency coding variants in the $G B A$ gene $[2,4,7,10$, 13-16].

Non-coding variants are the most significant single nucleotide polymorphisms (SNPs) identified near the MAPT and SNCA genes by GWAS [4]. To date, the functional variants driving such associations are unknown. We hypothesize that low frequency or rare coding variants can be identified by re-sequencing the $M A P T$ and SNCA genes. In addition, deep-sequencing $L R R K 2$ and GBA genes can not only identify additional untested coding risk variants but also protective alleles, as previously reported in these genes [17].

Highly penetrant mutations in the SNCA and LRRK2 genes are found in families with autosomal dominant inheritance, whereas autosomal recessive families with a typical PD phenotype carry mutations in the PARK2/ PARKIN, PARK6/PINK1 and PARK7/DJ-1 genes [18]. Most genetic studies in PD have focused on sequencing a particular Mendelian gene in familial or early onset $\mathrm{PD}$, or have directly screened few variants in sporadic PD cases in small samples [18]. A systematic study that sequences all of these genes (SNCA, LRRK2, PARK2, PINK1 and PARK7) in a large PD dataset has not been reported in European Americans [19, 20]. Thus, we used next-generation sequencing technology to re-sequence five Mendelian and the top GWAS susceptibility PD genes in a well-characterized case-control European American dataset (478 cases and 337 healthy controls) to identify both risk and protective low frequency or rare variants for PD.

\section{Results}

We performed pooled DNA-targeted deep-sequencing of the protein-coding regions of 7 genes, including 5 genes previously reported to most frequently cause familial forms of PD (SNCA, LRRK2, DJ-1, PARK2 and $P I N K 1)$ and 2 genes that have significant associations in GWAS with sporadic PD (GBA and MAPT genes) in 478 PD patients and 337 healthy individuals of
European-American descent from the Washington University in Saint Louis Movement Disorder Clinic (Table 1) $[15,21]$. This cohort contains $83 \%$ late-onset PD (LOPD) and $74 \%$ sporadic PD cases.

\section{Rare variants in a European American case-control sample}

We validated missense and splice-affecting variants with a predicted minor allele frequency (MAF) $<5 \%$. In this European-American descent sample, a total of 47 lowfrequency $(0.5-5 \%)$ and rare $(<0.5 \%)$ non-synonymous coding variants were validated. $36.2 \%(17 / 47)$ of the variants are found in LRRK2, $21.2 \%(10 / 47)$ in GBA, $17 \%$ (8/47) in PARK2, 14.9 \% (7/47) in PINK-1, $8.5 \%(4 / 47)$ in MAPT and $2.1 \%(1 / 47)$ in DJ-1 (Table 2). $70 \%$ of these variants are either singletons $(24 / 47)$ or doubletons (9/47).

\section{Novel variants}

$8.5 \%(4 / 47)$ of the total variants are novel and not present in public databases (accessed on June 11th, 2015). All of the novel singleton variants located on LRRK2, p.D1887N and p.S885C, and GBA, p.T336S genes are present exclusively in LOPD patients (Table 3 ). The PINK1 p.R147C, variant was found in one control individual but was not present in public datasets.

\section{Copy number analysis}

We observed a single structural genomic variant in a 70year-old man with a family history of PD $(1 / 126 ; 0.8 \%$; Fig. 1). B allele frequency and $\log \mathrm{R}$ ratio indicate that this variant is an intra-chromosomal duplication at the SNCA locus. We did not identify this duplication, or any duplication at this locus, in control individuals. No other exonic rearrangements were observed in any PD patient in the PARK2, DJ-1 or PINK-1 loci.

\section{Known pathogenic variants}

$91.5 \%(43 / 47)$ of the validated variants are reported in the PD mutation database [22]. Among the previously known variants, $7 \%(3 / 43)$ are considered Mendelian pathogenic mutations for PD (LRRK2 p.G2019S, PINK1 p.R492X and PARK2 p.D53X) (Table 4). Six out of eight LRRK2 p.G2019S carriers reported PD family history. Thus, in this sample, $0.6 \%(2 / 352)$ of the sporadic PD

Table 1 Summary of the sample demographics

\begin{tabular}{llllll}
\hline Series & $\mathrm{n}$ & Age at onset mean \pm SD $($ range) in years & Age at clinical assessment mean \pm SD (range) in years & Male: Female ratio & Caucasian (\%) \\
\hline Total PD & 478 & $61.3 \pm 10.6(40-86)$ & $67.6 \pm 10.0(41-90)$ & $297: 181$ & 99 \\
Familial PD & 126 & $59.0 \pm 10.9(40-85)$ & $65.8 \pm 11.0(42-86)$ & $73: 53$ & 89 \\
EOPD & 83 & $44.68 \pm 2.95(38-49)$ & $53.4 \pm 6.6(43-71)$ & $117: 220$ & 99 \\
Control & 337 & $64.8 \pm 10.2(30-85)$ & 92 \\
\hline
\end{tabular}


Table 2 Summary of the variants found in the European-American case-control sample

\begin{tabular}{|c|c|c|c|c|c|c|c|c|}
\hline Gene & AA change & Cases (478) & MAF & Controls (337) & MAF & $p$ value & Clinical interpretation PD mutation database & Notes \\
\hline \multirow[t]{17}{*}{ LRRK2 } & $\mathrm{R} 50 \mathrm{H}$ & 0 & 0 & 1 & 0.001 & n.s. & Unknown & \multirow[t]{18}{*}{ Autosomal Dominant } \\
\hline & R521G & 0 & 0 & 1 & 0.001 & n.s. & Unknown & \\
\hline & R793M & 0 & 0 & 2 & 0.003 & 0.09 & Pathogenic nature unclear & \\
\hline & $\mathrm{S} 885 \mathrm{C}$ & 1 & 0.001 & 0 & 0 & n.s. & Novel & \\
\hline & L119P & 2 & 0.002 & 1 & 0.001 & n.s. & Non-pathogenic & \\
\hline & P1262A & 1 & 0.001 & 0 & 0 & n.s. & Non-pathogenic & \\
\hline & I1371V & 2 & 0.002 & 0 & 0 & n.s. & Pathogenic nature unclear & \\
\hline & V1389| & 1 & 0.001 & 0 & 0 & n.s. & Unknown & \\
\hline & V1450l & 0 & 0 & 1 & 0.001 & n.s. & Not pathogenic & \\
\hline & R1514Q & 7 & 0.007 & 4 & 0.006 & n.s. & Not pathogenic & \\
\hline & M1646T & 21 & 0.022 & 9 & 0.013 & n.s. & Not pathogenic/Risk & \\
\hline & L1795F & 1 & 0.001 & 0 & 0 & n.s. & Pathogenic nature unclear & \\
\hline & D1887N & 1 & 0.001 & 0 & 0 & n.s. & Novel & \\
\hline & G2019S & 8 & 0.008 & 0 & 0 & 0.02 & Pathogenic & \\
\hline & N2081D & 17 & 0.018 & 15 & 0.022 & n.s. & Non-pathogenic & \\
\hline & Y2189C & 0 & 0 & 1 & 0.001 & n.s. & Pathogenic nature unclear & \\
\hline & A2461V & 0 & 0 & 1 & 0.001 & n.s. & Unknown & \\
\hline Total & & 62 & & 36 & & & & \\
\hline DJ-1 & A179T & 1 & 0.0010 & 0 & 0 & n.s. & Pathogenic nature unclear & Autosomal Recessive \\
\hline Total & & 1 & & 0 & & & & \\
\hline \multirow[t]{8}{*}{ PARKIN } & D53X & 1 & 0.001 & 0 & 0 & n.s. & Pathogenic & \multirow[t]{8}{*}{ Autosomal Recessive } \\
\hline & R65C & 1 & 0.001 & 1 & 0.001 & n.s. & Pathogenic nature unclear & \\
\hline & A82E & 1 & 0.001 & 1 & 0.001 & n.s. & Pathogenic nature unclear & \\
\hline & R275W & 2 & 0.002 & 2 & 0.003 & n.s. & Pathogenic nature unclear & \\
\hline & E310D & 0 & 0 & 1 & 0.001 & n.s. & Pathogenic nature unclear & \\
\hline & R402C & 5 & 0.005 & 1 & 0.001 & n.s. & Pathogenic nature unclear & \\
\hline & $\mathrm{R} 402 \mathrm{H}$ & 0 & 0 & 1 & 0.001 & n.s. & Unknown & \\
\hline & P437L & 3 & 0.003 & 2 & 0.003 & n.s. & Pathogenic nature unclear & \\
\hline Total & & 13 & & 9 & & & & \\
\hline \multirow[t]{7}{*}{ PINK1 } & R147C & 0 & 0 & 1 & 0.001 & n.s. & Novel & \multirow[t]{7}{*}{ Autosomal Recessive } \\
\hline & R207Q & 1 & 0.001 & 0 & 0 & n.s. & Unknown & \\
\hline & M318L & 0 & 0 & 1 & 0.001 & n.s. & Pathogenic nature unclear & \\
\hline & A339S & 2 & 0.002 & 1 & 0.001 & n.s. & Pathogenic nature unclear & \\
\hline & N367S & 2 & 0.002 & 0 & 0 & n.s. & Pathogenic nature unclear & \\
\hline & G411S & 1 & 0.001 & 0 & 0 & n.s. & Pathogenic nature unclear & \\
\hline & R492X & 0 & 0 & 1 & 0.001 & n.s. & Pathogenic & \\
\hline Total & & 6 & & 4 & & & & \\
\hline \multirow[t]{6}{*}{$\mathrm{GBA}^{\mathrm{c}}$} & $\mathrm{R} 83 \mathrm{C}$ & 2 & 0.002 & 0 & 0 & n.s. & Unknown & \multirow[t]{6}{*}{ PD GWAS Hit } \\
\hline & $\mathrm{H} 294 \mathrm{Q}$ & 2 & 0.002 & 0 & 0 & n.s. & Pathogenic & \\
\hline & T336S & 1 & 0.001 & 0 & 0 & n.s. & Novel & \\
\hline & E365K & 19 & 0.020 & 11 & 0.02 & n.s. & Polymorphism, Risk PD & \\
\hline & $\mathrm{T} 408 \mathrm{M}$ & 17 & 0.018 & 0 & 0 & 0.0005 & Polymorphism & \\
\hline & N409S & 7 & 0.007 & 1 & 0.001 & 0.09 & Pathogenic, Risk PD & \\
\hline
\end{tabular}


Table 2 Summary of the variants found in the European-American case-control sample (Continued)

\begin{tabular}{|c|c|c|c|c|c|c|c|c|}
\hline & E427K & 1 & 0.001 & 0 & 0 & n.s. & Unknown & \\
\hline & $\mathrm{D} 448 \mathrm{H}$ & 1 & 0.001 & 1 & 0.001 & n.s. & Pathogenic $^{a}$ & \\
\hline & L483P & 7 & 0.007 & 2 & 0.003 & n.s. & Pathogenic ${ }^{\mathrm{a}}$, Risk PD & \\
\hline & A495P & 17 & 0.018 & 10 & 0.015 & n.s. & Pathogenic $^{b}$ & \\
\hline Total & & 74 & & 25 & & 0.001 & & \\
\hline \multirow[t]{4}{*}{ MAPT } & $\mathrm{A} 152 \mathrm{~T}$ & 4 & 0.004 & 0 & 0 & 0.09 & Risk AD, FTD & PD GWAS Hit \\
\hline & S427F & 0 & 0 & 2 & 0.003 & 0.09 & Unknown & \\
\hline & A495T & 0 & 0 & 1 & 0.001 & n.s. & Non-pathogenic & \\
\hline & A556T & 1 & 0.001 & 0 & 0 & n.s. & Unknown & \\
\hline Total & & 5 & & 3 & & & & \\
\hline
\end{tabular}

Gene: official Symbol provide by HGNC; AA Change: amino acid change resulting from the observed variant; MAF: Minor allele frequency; Clinical Interpretation: Clinical interpretation is based on PD mutation database [22] and published papers. ${ }^{\mathrm{a}} \mathrm{GBA}$ variants found in pseudo gene. ${ }^{\mathrm{b}}$ Variant also known as p.A485P ${ }^{\mathrm{c}}$ Amino acid designations are based on the primary GBA translation product, including the 39-residue signal peptide

patients and a $4.8 \%(6 / 126)$ of the familial PD subjects carry the LRRK2 p.G2019S mutation. The PARK2 p.D53X mutation heterozygous carrier is an EOPD patient with a positive family history. The PINK1 p.R492X heterozygous carrier is an asymptomatic 68-year old individual with no family history of PD (Table 4).

Of all the previously known variants in all sequenced genes, $11.6 \%(5 / 43)$ are located in the $G B A$ gene (p.H294Q, p.D448H, p.N409S, p.L483P and p.A495P) and cause Gaucher disease (Table 2). We found that these variants are overrepresented in the PD patient sample, but did not reach statistical significance $(p=0.08$; $\mathrm{OR}=1.76,95 \% \mathrm{CI}=0.93-3.34)$. Two $G B A$ variants, p.T408M and p.E365K, previously described as nonpathogenic polymorphisms for Gaucher disease, are significantly enriched $(p=0.01 ; \mathrm{OR}=2.35,95 \% \mathrm{CI}=1.19-$ 4.66) in PD patients $(7.5 \% ; 36 / 478)$ compared with controls $(3.2 \% ; 11 / 337)$.

\section{Variants of unclear and unknown pathogenicity}

$34.9 \%(15 / 43)$ of the variants located on LRRK2 (four variants), PARK2 (six variants), PINK1 (4 variants) and PARK7 (one variant) have been reported previously and their pathogenicity is unclear (Table 2). Although the cumulative frequency of these variants is higher in PD patients $(4.4 \%)$ compared to controls $(3.8 \%)$, this difference is not statistically significant $(p=0.7 ; \mathrm{OR}=$ $1.14,95 \% \mathrm{CI}=0.56-2.32$ ), suggesting that either most of these variants are very unlikely to be true risk factors for PD or our sample size is not large enough to detect such differences.

There are 10 variants $(21.3 \%)$ with an unknown role in PD. In this cohort, $1.2 \%$ of PD patients and $1.8 \%$ of controls were found to carry one of these variants $(p=0.5 ; \mathrm{OR}=0.70,95 \% \mathrm{CI}=0.22-2.19)$.

The non-pathogenic variants, constituting $16.3 \%(7 / 43)$ of the variants, were found in a similar proportion of PD patients $(10 \%)$ and controls (9.2\%) $(p=0.68$; OR $=1.10,95 \%$ $\mathrm{CI}=0.68-1.77)$, supporting their role as non-pathogenic.

\section{Single-variant analysis}

The minor allele of GBA p.T408M $\left(p=4.9 \times 10^{-4}\right)$ is associated with increased PD risk after multiple-testing correction (Table 2). The GBA p.T408M variant is present in 3.5 $\%(17 / 478)$ of the total number of PD cases and in none of the control group (Table 2). In addition, we found a nominal association with $L R R K 2$ p.G2019S $(p=0.02)$ (Table 2). Using publicly available data from the exome variant server (EVS, European American) and Exome Aggregation Consortium (ExAc, European non-Finish) as controls, the variants p.T408M $\left(p=9.0 \times 10^{-4} ; p=1.0 \times 10^{-2}\right)$, p.L483P $\left(p<1.0 \times 10^{-4}\right.$; not found in ExAc), p.R83C $\left(p=1.0 \times 10^{-2}\right.$; $\left.p=1.0 \times 10^{-4}\right)$, p.N409S $\left(p=2.0 \times 10^{-2} ; p=6.0 \times 10^{-2}\right)$, p.H294Q $\left(p=4.0 \times 10^{-2} ; p=1.0 \times 10^{-2}\right)$ and p.E365K $\left(p=4.0 \times 10^{-2} ; p=2.0 \times 10^{-2}\right)$ in the GBA gene, p.G2019S $\left(p<1.0 \times 10^{-4} ; p<1.0 \times 10^{-4}\right)$ and

Table 3 Summary of the individuals with novel variants in PD genes

\begin{tabular}{llllllllll}
\hline Gene & AA & Location (Chr:bp) & ID & Ethnicity & AAO & PD FAM HISTORY & Gender & Dementia & MMSE \\
\hline PINK1 & R147C & $1: 20964386$ & 1 & Caucasian & NA & NO & F & NA & NA \\
LRRK2 & S885C & $12: 40681305$ & 2 & Caucasian & 67 & NO & F & Yes & 28 \\
LRRK2 & D1887N & $12: 40722164$ & 3 & Caucasian & 55 & NO & M & No & 30 \\
GBA & T336S & $1: 155206254$ & 4 & Caucasian & 62 & NO & F & Possible & 27 \\
\hline
\end{tabular}




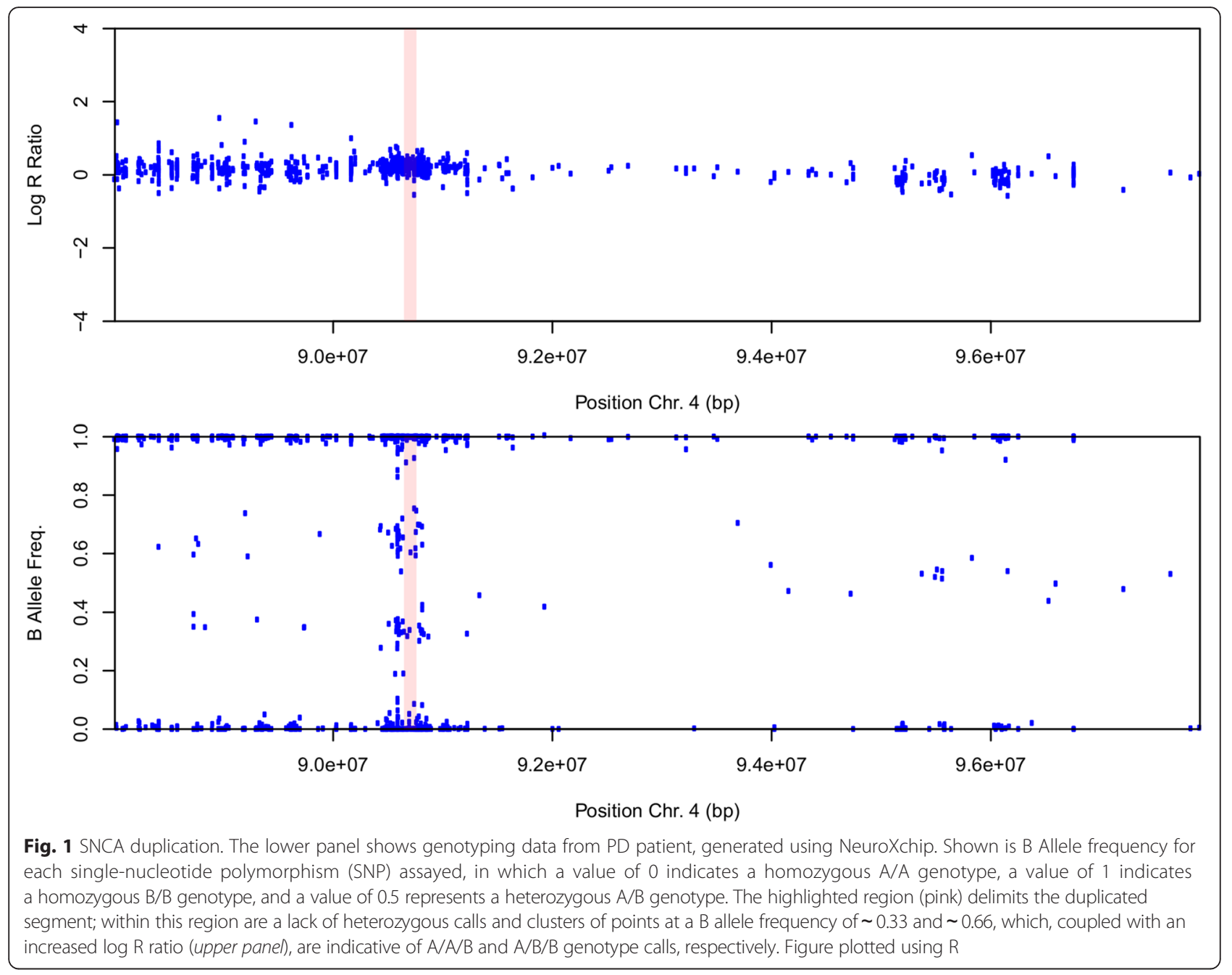

p.M1646T (not found in EVS; $p=3.0 \times 10^{-2}$ ) in the LRRK2 gene and PINK1 p.N367S (Not found in EVS; $p=1.0 \times 10^{-4}$ ) all achieved statistical significance in at least one of the control populations studied (Table 5).
The MAPT p.A152T variant has been associated with other neurodegenerative diseases including $\mathrm{AD}$ and frontotemporal dementia (FTD) [23]. In our study, the MAPT p.A152T variant occurs in $0.8 \%(4 / 478)$ of $\mathrm{PD}$ cases but in none of the controls $(0 / 337, p=0.09)$.

Table 4 Summary of the individuals with pathogenic mutations in PD genes

\begin{tabular}{|c|c|c|c|c|c|c|c|c|c|}
\hline Gene & AA & rs\# & ID & Ethnicity & $\mathrm{AAO}$ & PD FAM HISTORY & Gender & Dementia & MMSE \\
\hline \multirow[t]{8}{*}{ LRRK2 } & G2019S & rs34637584 & 1 & Caucasian & 42 & YES & M & No & 30 \\
\hline & & & 2 & Caucasian & 62 & YES & $\mathrm{F}$ & No & 30 \\
\hline & & & 3 & Caucasian & 63 & YES & M & No & 30 \\
\hline & & & 4 & Caucasian & 68 & YES & M & Yes & 16 \\
\hline & & & 5 & Caucasian & 70 & YES & M & No & 30 \\
\hline & & & 6 & Caucasian & 77 & NO & M & Yes & 25 \\
\hline & & & 7 & Caucasian & 51 & YES & $\mathrm{F}$ & Possible & 23 \\
\hline & & & 8 & Caucasian & 59 & NO & $\mathrm{F}$ & No & 29 \\
\hline PARK2 & D53Stop & $6: 162864360$ & 9 & Caucasian & 50 & YES & M & Possible & 28 \\
\hline PINK1 & $\mathrm{R} 492 \mathrm{X}$ & rs34208370 & 10 & Caucasian & NA & NO & M & Possible & 24 \\
\hline
\end{tabular}


Table 5 Frequency of validated variants in public databases

\begin{tabular}{llcllllll}
\hline Gene & AA change & MAF PD patients & EVS MAF & $p$ value & OR (IC 95 \%) & ExAC MAF & $p$ value & OR (IC 95 \%) \\
\hline LRRK2 & G2019S & 0.008 & 0.0006 & $<0.0001$ & $12.67(4.0-40.2)$ & 0.00063 & $<0.0001$ & $13.4(6.2-28.6)$ \\
& M1646T & 0.022 & 0.0154 & n.s. & & 0.01424 & 0.03 & $1.58(1.02-2.45)$ \\
PINK1 & N367S & 0.002 & Not found & & & 0.00002 & 0.0001 & $139.6(12.6-1541)$ \\
GBA & H294Q & 0.002 & 0.0003 & 0.04 & $6.0(1.0-35.99)$ & 0.0004 & 0.01 & $5.82(1.37-24.7)$ \\
& R83C & 0.002 & 0.0001 & 0.01 & $18.02(1.63-199)$ & $7.5086 \mathrm{E}-05$ & 0.0001 & $27.9(5.4-144)$ \\
& N409S & 0.007 & 0.0028 & 0.02 & $2.63(1.13-6.13)$ & $3.6300 \mathrm{E}-03$ & 0.06 & $2.03(0.95-4.31)$ \\
& L483P & 0.007 & 0.0005 & $<0.0001$ & $15.85(4.63-54.24)$ & Not found & & \\
& T408M & 0.018 & 0.0072 & 0.0009 & $2.49(1.45-4.28)$ & 0.010 & 0.01 & $1.85(1.14-3.01)$ \\
& E365K & 0.020 & 0.0121 & 0.04 & $1.65(1.01-2.71)$ & 0.012 & 0.02 & $1.69(1.06-2.67)$ \\
MAPT & A152T & 0.004 & 0.0027 & 0.4 & $1.56(0.54-4.54)$ & 0.002 & 0.07 & $2.5(0.92-6.82)$ \\
\hline
\end{tabular}

\section{Gene-burden analyses}

To determine whether rare variants in the $L R R K 2$, DJ1, PARK2, PINK1, GBA or MAPT genes contribute collectively to PD risk, we performed a gene-burden association test using the optimal SNP-set sequence kernel association test (SKAT-O) [24]. Gene-based association testing achieved significance for $G B A$ (PSKAT-O $=7.0 \times 10^{-4}$; OR $=2.28$ (1.41-3.68). Importantly, the most commonly reported $G B A$ risk variants (p.N409S and p.L483P) occur in $2.9 \%(14 / 478)$ of the PD cases and in $0.9 \%(3 / 337)$ of the controls $(p=0.05$; $\mathrm{OR}=3.35,95 \% \mathrm{CI}=0.95-11.8)$. When we exclude p.N409S and p.L483P from the analysis, the role of $G B A$ in $\mathrm{PD}$ risk remains significant $\left(p=4.9 \times 10^{-3}\right.$; $\mathrm{OR}=2.04,95 \% \mathrm{CI}=1.24-3.37)$, suggesting that additional variants in this gene also increase risk for PD. When we exclude p.T408M from the analysis, the risk of PD conferred by $G B A$ variants is not significant $(p=0.39$ ), which suggests that p.T408M may be the primary driver of the association with PD risk. These findings highlight the importance and necessity to sequence the entire $G B A$ gene as opposed to genotyping only known risk variants for PD.

We also found a significant enrichment of coding variants in the LRRK2 gene in PD cases compared to controls $(p=0.01, \quad \mathrm{OR}=1.86,95 \% \mathrm{CI}=1.14-3.02)$ (Table 6), which suggests that there are other risk variants in the LRRK2 gene in addition to the known pathogenic p.G2019S mutation.

No significance was found for the MATP2, PARKIN, PINK1 and DJ-1 genes

\section{Effect on age at onset (AAO) of PD}

$G B A$ variant carriers tend to exhibit an earlier AAO than non-carriers [25]. Thus, we tested whether $G B A$ variants affect $\mathrm{AAO}$; we found that $G B A$ variants carriers have a earlier AAO than non-carriers (54 years. vs. 62 years.; $p<0.0001$ ) (Fig. 2a). Interestingly, when restricted to carriers and non-carriers of p.N408M using the same model, carriers had a 5.0-year-earlier onset than noncarriers (57 years. vs. 62 years.; $p=0.006$ ) (Fig. $2 b$ ).

\section{Discussion}

Disease-causing variants in the SNCA, LRRK2, PARKIN, PINK1 and $D J-1$ genes have been found in familial early onset forms of PD [18]. In this study, we systematically screened for rare variants and pathogenic mutations in the SNCA, LRRK2, PARK2, PINK1, PARK7, MAPT and $G B A$ genes in a series of well-characterized PD casecontrol samples. A total of 47 low-frequency and rare non-synonymous coding variants were validated.

\section{Most common pathogenic variants in this cohort}

Nine individuals $(1.9 \%)$ of the total sample of PD patients carry a known pathogenic mutation in two Mendelian genes, LRRK2 p.G2019S and PARK2 p.D53X. Among patients with a family history of PD, $5.6 \%$ (7/126) carry a known pathogenic mutation. In this cohort, we found that among the sequenced genes, the $L R R K 2$ gene was enriched with multiple variants, accounting for $36.2 \%$ of all the validated variants. The LRRK2 p.G2019S mutation is significantly associated with risk of $\mathrm{PD}$ and occurs in $1.7 \%$ of $\mathrm{PD}$ patients.

Table 6 Gene-based analyses for Mendelian and GWAS PD genes

\begin{tabular}{lclll}
\hline Gene & CMAF PD cases & CMAF controls & $P$ & OR \\
\hline GBA & 0.084 & 0.034 & 0.0007 & $2.28(1.41-3.68)$ \\
LRRK2 & 0.069 & 0.034 & 0.01 & $1.86(1.14-3.02)$ \\
DJ-1 & 0.001 & 0 & 0.64 & $2.1(0.08-52.1)$ \\
PARKIN & 0.014 & 0.012 & 0.96 & $1.01(0.43-2.40)$ \\
PINK1 & 0.006 & 0.005 & 0.93 & $1.05(0.29-3.77)$ \\
MAPT & 0.005 & 0.004 & 0.82 & $1.17(0.27-4.95)$ \\
\hline
\end{tabular}

Results of SKAT-O analyses including all the validated coding variants were presented. $\mathrm{CMAF}=$ cummulative $\mathrm{MAF}$ 
a

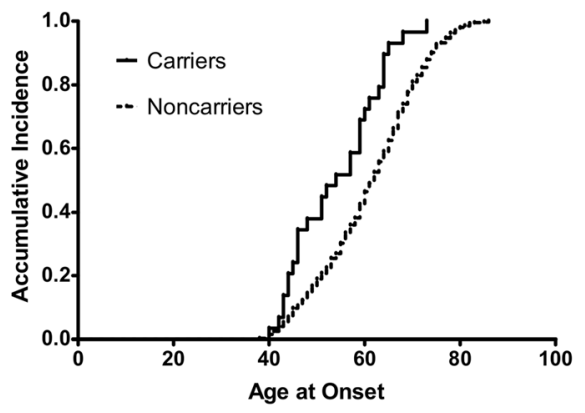

b

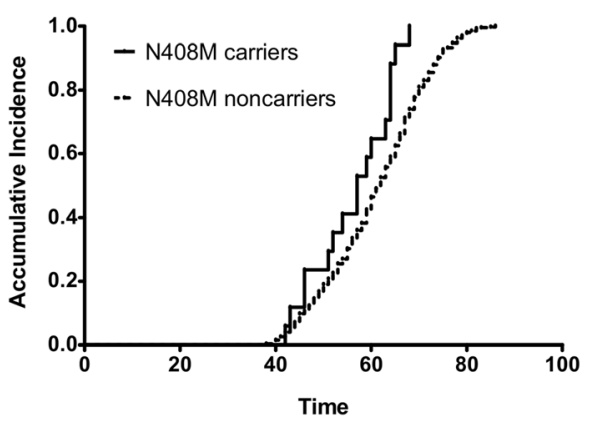

Fig. 2 a. Cumulative incidence rates of PD among carriers and non-carriers of all GBA variants. b. Cumulative incidence rates of PD among carriers and non-carriers of the p.N408M variant. Survival fractions were calculated using the Kaplan-Meier method and significant differences were calculated by Log-rank test

Interestingly, mutation carriers were clinically indistinguishable from idiopathic $\mathrm{PD}$, which support the evidence for involvement of this gene in late-onset sporadic PD. A recent meta-analysis reported that the mean frequency of the LRRK2 p. G2019S mutation in sporadic PD patients among studies in the U.S. is $0.4 \%$ [26]. Meanwhile, another international multi-center study reports only 49 of 8371 (0.6 \%) PD patients of European and Asian origin carry the LRRK2 p. G2019S mutation [17]. Both frequencies are similar to the frequency reported here of $0.6 \%(2 /$ 352 ) in sporadic PD patients. Our gene-based analysis found a significant association with the LRRK2 gene, which suggests that there are additional risk variants in $L R R K 2$ affecting PD risk.

We also detected a SNCA locus duplication in a 70year-old man with a family history of PD (1/126; $0.8 \%$; Fig. 1) and a 3-year history of parkinsonism. This PD patient exhibited clinical features indistinguishable from idiopathic PD. As expected, we found no coding mutations in the $S N C A$ gene in this cohort. Point mutations in the $S N C A$ gene are extremely rare and have been identified mostly in familial and EOPD [18]. The most common variation found in the SNCA gene are copy number variations (CNVs). SNCA duplications are not fully penetrant and are associated with variable clinical features, ranging from early-onset with dementia and psychiatric features to late-onset sporadic [27].

A recent report examining rare variants in the main Mendelian PD genes in a small case-control sample consisting of 249 cases and 145 controls of European origin (Spanish) found an enrichment of rare functional variants in PD cases [20]. They reported that up to $3.6 \%$ of patients with sporadic PD are carriers of known pathogenic mutations in different Mendelian genes. The difference in the frequency of pathogenic mutations reported here $(1.9 \%)$ and that reported by Spataro (3.6 \%) [20] is likely due to differences in methodology (exome sequencing data vs pooled-targeted sequencing) and to the different genetic background of the samples (Spanish vs North American).

\section{Most common risk variants in this cohort}

Heterozygous mutations in the GBA gene can be considered as low penetrance variants with autosomal dominant inheritance for PD [28]. In this study, fifty-three (11 $\%)$ of the PD patients and fifteen (4.5\%) controls carry heterozygous variants in the $G B A$ gene $(p=1.0$ $\left.\times 10^{-3} ; \mathrm{OR}=2.17,95 \% \mathrm{CI}=1.36-3.46\right)$, which indicate that $G B A$ coding variants increase risk for PD in this cohort. We also have demonstrated that those patients with PD carrying a $G B A$ variant experience a disease onset 6 years earlier than patients without $G B A$ variants. Interestingly, $G B A$ variants mainly affect $A A O$ of LOPD patients. Two GBA variants (p.N409S and p.L483P) have consistently been reported to be associated with increased PD risk in both, Ashkenazi Jewish and nonAshkenazi populations [29]. Here, the p.N409S $(\mathrm{MAF}=$ $0.007)$ and p.L483P (MAF $=0.007)$ variants, are present in $2.9 \%(14 / 478)$ of PD patients and $0.9 \%(3 / 337)$ of controls. These allelic frequencies agree with previous reports [29]. We found that both variants are overrepresented in PD cases compared to controls, but they only reached statistical significance after including a larger control sample from publicly available databases. In addition, we report for the first time, an association between PD risk and the GBA variant p.T408M (MAF: 0.018). p.T408M is considered a polymorphism because it has been found in control populations $[25,30]$. In this dataset, the GBA p.T408M variant drives the gene-based association with risk for PD. In the largest Non-Ashkenazi case-control sample studied to date, the GBA p.T408M variant was not significantly associated with PD [29]. This discrepancy could be explained by the heterogeneity of populations included in that study as it was enriched with individuals from populations in which the p.T408M variant is absent or very rare. The p.E365K allele is a 
hypomorphic variant (42.7\% of wild type activity) [31] often found in cis or trans with other Gauchercausing non-synonymous mutations [32], exhibiting a frequency that is similar in controls and Gaucher patients [33]. We found that p.E365K achieves nominal significance $(p=0.02 ; \mathrm{OR}=1.69,95 \% \mathrm{CI}=1.06-2.67)$ after including controls from public databases. Interestingly, the OR found here is similar to those reported previously [33, 34]. Both p.T408M and p.E365K have been described as "mild" mutations or modifier alleles. In our study, we did not observe a "second" mutation that occurred with either p.T408M or p.E365K, which suggests a second hit may exist as an interacting factor, similar to those described in a traditionally considered non-pathogenic variant in $\mathrm{AD}$ [35]. Interestingly, we found seven PD patients carrying PD risk variants in two of all screened genes, further suggesting a double-hit mechanism impacting the risk for PD (Table 7), as reported by the presence of variants in the $L R R K 2$ and GBA genes in PD patients [36].

We also found that the MAPT p.A152T variant occurs in $0.8 \%(4 / 478)$ of PD cases but in none of the controls $(0 / 337, p=0.09)$. It is possible that the MAPT p.A152T variant increases PD risk, but this association needs further confirmation in additional series.

Among the eight variants validated in PARK2, we found a stop-codon, p.D53X, in an EOPD (early onset $\mathrm{PD})$ patient with a family history of PD. We also found one control individual carried the PINK1 (p.R492X) variant. We validated just a single variant $D J-1$, p. A179T in a 56 year old PD patient with no family history of PD. All of these variants in recessive genes were found a heterozygous manner. Truly causative variants in PARK2, PINK1 or DJ-1 are present in a homozygous or heterozygous compound manner, but we cannot exclude the possible role of heterozygous variants on risk of sporadic PD. It is important to highlight that the most common pathogenic mutations in these genes are exon rearrangements or copy number variations. We did not detect exonic rearrangements in these genes in our cohort. The high proportion (83 \%) of LOPD and sporadic cases $(74 \%)$ in our sample may explain the low number of validated variants found in the recessive genes.

\section{Novel variants}

We uncovered four novel variants (LRRK2, p.D1887N and p.S885C), (PINK1, p.R147C), and (GBA, p.T336S) in $0.8 \%$ of PD cases. LRRK2, p.D $1887 \mathrm{~N}$ is located in the kinase domain and could play a functional role. The rareness of and the impossibility to expand the segregation studies with these variants to additional family members make its clinical interpretation challenging. However, finding novel variants in sporadic late onset PD suggests that it is possible to uncover such variants in genes linked to Mendelian PD or even in PD cases with an unclear pattern of inheritance. This is supported by our gene-based analysis, which demonstrates that additional untested variants in the GBA and $L R R K 2$ genes contribute to the role of these genes in PD risk.

\section{Conclusions}

In summary, our results confirm the strong effect of GBA and LRRK2 on sporadic PD risk. However, our gene-based analyses demonstrates that non-synonymous $G B A$ variants can have a greater impact on PD risk than $L R R K 2$. In this cohort, the more common pathogenic mutations are located in the LRRK2 gene. Multiple GBA gene variants confer the highest risk for PD in our sample. We report novel interactions between variants in the GBA and LRRK2 genes as double hits affecting PD patients with no family history of PD. Our results also suggest that novel and untested variants in the $G B A$ and $L R R K 2$ genes influence PD risk. This has important implications on the genetic information provided to patients and families and potential new therapeutic

Table $\mathbf{7}$ Individuals carrying two rare variants

\begin{tabular}{lllllllllll}
\hline Individual & Ethnicity & AAO & PD FAM HISTORY & Gender & Age at draw & rs & Variant in GBA & rs\# & Second Hit & Both genes \\
\hline PD Patient & Caucasian & 56 & NO & F & 66 & rs71653622 & A179T & rs2230288 & E365K & GBA and PARK7 \\
Control & Caucasian & NA & NO & F & 65 & rs421016 & L483P & rs1064651 & D448H & GBA and GBA \\
PD Patient & Caucasian & 46 & NO & F & 57 & rs76763715 & N409S & rs75548401 & T408M & GBA and GBA \\
PD Patient & Caucasian & 63 & NO & M & 77 & rs1141812 & R83C & rs33995883 & N2081D & GBA and LRRK2 \\
PD Patient & Caucasian & 82 & NO & M & 87 & rs368060 & A495P & rs33995463 & L119P & GBA and LRRK2 \\
Control & Caucasian & NA & NO & M & 66 & rs421016 & L483P & rs35658131 & Y2189C & GBA and LRRK2 \\
PD Patient & Caucasian & 59 & YES & F & 61 & rs76763715 & N409S & rs33995883 & N2081D & GBA and LRRK2 \\
PD Patient & Caucasian & 73 & NO & M & 75 & rs76763715 & N409S & rs33995883 & N2081D & GBA and LRRK2 \\
Control & Caucasian & NA & NO & F & 65 & rs368060 & A495P & rs34424986 & R275W & GBA and PARK2 \\
PD Patient & Caucasian & 44 & NO & M & 50 & rs76763715 & N409S & rs45478900 & G411C & GBA and PINK1 \\
\hline
\end{tabular}


approaches for PD patients. Our findings also strongly support the role of the lysosomal system as a pathogenic pathway in PD. Further work is necessary to clarify the role of specific and very rare variants in these genes on risk and PD phenotype.

\section{Methods}

\section{Ethics statement}

The Institutional Review Board (IRB) at the Washington University School of Medicine in Saint Louis approved the study. Prior to their participation, written informed consent was reviewed and obtained from family members. The Human Research Protection Office (HRPO) approval number for our ADRC Genetics Core family studies is 201104178 .

\section{Samples}

Samples included 478 PD patients and 337 healthy individuals from the Washington University in Saint Louis Movement Disorder Clinic (MO, USA) [15, 21, 37]. All were examined by experienced movement disorder clinicians (J.S.P.). PD diagnosis was established according to the UK Brain Bank criteria.

\section{Statistical and association analyses}

For each variant, allele frequencies were calculated in cases and controls, and a $\chi^{2}$ test on allelic association was performed. A $p$-value of 0.05 was set as nominal significance threshold. The multiple-testing correction cutoff for the single-variant analysis using Bonferroni correction for 47 tests is $1.0 \times 10^{-3}(0.05 / 47)$. We used Plink (http://pngu.mgh.harvard.edu/ purcell/plink/) to analyze associations [38]. The gene-based association was performed using SKAT-O, which utilizes the $\mathrm{R}$ package SKAT [24]. All variants were included in the model independent of their clinical interpretation. The influence of the genetic variants on AAO was carried out using the Kaplan-Meier method and tested for significant differences using a log-rank test.

\section{Pooled-DNA sequencing experiment}

Pooled-DNA sequencing was performed as described previously $[35,39,40]$. Briefly, equimolar amounts of individual DNA samples were pooled together after being measured using Quant-iT PicoGreen reagent. Two different pools with $100 \mathrm{ng}$ of DNA from 114 and 98 individuals were made. The coding exons and flanking regions (a minimum of $50 \mathrm{bp}$ each side) were individually PCR amplified using specific primers and Pfu Ultra high-fidelity polymerase (Stratagene). An average of 20 diploid genomes (approximately 0.14 ng DNA) per individual were used as input for a total of 62 PCR reactions that covered 46,319 bases from the 7 genes. PCR products were cleaned using QIAquick PCR purification kits, quantified using Quant-iT PicoGreen reagent and ligated in equimolar amounts using T4 Ligase and T4 Polynucleotide Kinase. After ligation, concatenated PCR products were randomly sheared by sonication and prepared for sequencing on an Illumina Genome Analyzer IIx (GAIIx) according to the manufacturer's specifications. pCMV6-XL5 amplicon (1908 base pairs) was included as a negative control. As positive controls, ten different constructs (p53 gene) with synthetically engineered mutations at a relative frequency of one mutated copy per 250 normal copies were amplified and pooled with the PCR products. Six DNA samples heterozygous for previously known mutants in MAPT gene were also included. Single reads (36 bp) were aligned to the human genome reference assembly build 36.1 (hg18) using SPLINTER [41]. SPLINTER uses the positive control to estimate sensitivity and specificity for variant calling. The wild type: mutant ratio in the positive control is similar to the relative frequency expected for a single mutation in one pool (1 chromosome mutated in 125 samples $=1 / 250$ ). SPLINTER uses the negative control (first $900 \mathrm{bp}$ ) to model the errors across the 36-bp Illumina reads and to create an error model from each sequencing run of the machine. Based on the error model, SPLINTER calculates a $p$-value for the probability that a predicted variant is a true positive. A $p$-value at which all mutants in the positive controls were identified was defined as the cut-off value for the best sensitivity and specificity. All mutants included as part of the amplified positive control vector were found upon achieving $>30$-fold coverage at mutated sites (sensitivity $=100 \%$ ) and only $\sim 80$ sites in the $1908 \mathrm{bp}$ negative control vector were predicted to be polymorphic (specificity $=\sim 95 \%$ ). The variants with a $p$-value below this cut-off value were considered for follow-up confirmation.

\section{Genotyping}

All rare missense or splice site variants identified by SPLINTER were validated by directly genotyping all sequenced individuals using Sequenom iPLEX or KASPar genotyping systems as described previously [42-44]. The validated SNPs were then genotyped in all members of the series. An average coverage of 30 -fold per allele per pool is the minimum coverage necessary to obtain an optimal positive predictive value for the SNP-calling algorithm [41]. The necessary number of lanes to obtain a minimum of 30 -fold coverage per base and sample were run.

\section{Copy number variation analysis}

The B Allele frequency and Log R Ratio were used to identify genomic deletions and duplications as previously described [45] using NeuroX chip data [46]. 


\section{Bioinformatics}

The PD mutation database [22] was used to identify sequence variants previously found in other studies of familial PD and to determine whether or not they are considered to be disease-causative variants. The EVS (http://evs.gs.washington.edu/EVS/), SeattleSeq Annotation (http://snp.gs.washington.edu/SeattleSeqAnnotation137/), The Exome Aggregation Consortium (ExAC) http://exac.broadinstitute.org/ (June 19, 2015) and the Ensembl Genome Database (http://useast.ensembl.org/ index.html) were used to annotate the rare variants. Polyphen algorithms were used to predict the functional effect of the identified variants.

\section{Population structure}

A PCA was conducted to infer genetic structure of individuals who have GWAS data available using the EIGENSTRAT software as previously described [40]. Samples were excluded if not located within the EA cluster. Individuals who do not have GWAS data available were included in the study if the self-reported ethnicity was non-Hispanic European.

\section{Abbreviations}

AAO: age at onset; AD: Alzheimer's disease; Cl: confidence interval; CNVs: copy number variations; DJ-1: Daisuke-Junko-1; EOPD: early-onset Parkinson's disease; EVS: exome variant server: ExAc: exome aggregation consortium; FTD: frontotemporal dementia; GBA: glucocerebrosidase beta acid; GWAS: genome-wide association studies; LOPD: late-onset Parkinson's disease; LRRK2: leucine-rich repeat kinase 2; MAF: minor allele frequency; MAPT: microtubule-associated protein tau; OR: odd ratio; PD: Parkinson's disease; PINK1: PTEN-induced putative kinase 1; SKAT-O: SNP-set sequence kernel association test; SNCA: a-synuclein.

\section{Competing interests}

The authors declare that they have no competing interests.

\section{Authors' contributions}

$B A B$ and $C C$ conceived and designed the study. JSP, AAD, SOC, and PP acquired and analyzed the clinical data. $B A B, J C$, and $B C$ acquired the genetic data. BAB, JSC, $\mathrm{LI}$ and CC performed the statistical analysis and interpreted the genetic data. $B A B$ wrote the draft of the manuscript and JSP, AAD, SOC, PP, JC, BC, JSC, LI and CC provided critical comments on the draft of the manuscript. All authors read and approved the final version of the manuscript.

\footnotetext{
Acknowledgments

The authors thank the participants and their families, whose help and participation made this work possible. The authors wish to thank to Dr. Andrew B. Singleton for performing the copy number variation analysis reported in this manuscript. The authors wish to thank Susan Loftin and Karen Klumpp for their expert technical assistance. This work was supported by grants from NINDS (NS075321, NS041509, NS058714, and R01-AG035083); the Barnes Jewish Hospital Foundation (BJHF); the American Parkinson Disease Association (APDA) Advanced Research Center for Parkinson Disease at Washington University in St. Louis; the Greater St. Louis Chapter of the APDA; the Barnes Jewish Hospital Foundation (Elliot Stein Family Fund and Parkinson Disease Research Fund), The Michael J. Fox Foundation for Parkinson's Research, Alzheimer's Association and Weston Brain Institute (BAND-14-338165). This research was conducted while C.C. was a recipient of a New Investigator Award in Alzheimer's disease from the American Federation for Aging Research. C.C. is a recipient of a BrightFocus Foundation Alzheimer's Disease Research Grant (A2013359S). This study was supported by grants from the Spanish Ministry of Science and Innovation SAF2006-10126
}

(2006-2009), SAF2010-22329-C02-01 (2010-2012) and SAF2013-47939-R (2013-2016) to P.P. We thank Dr. Shonali Midha who provided editing of the manuscript.

\section{Author details}

'Department of Internal Medicine, School of Medicine, Washington University, 8007660 South Euclid Avenue, St. Louis, MO 63110, USA. ${ }^{2}$ Department of Neurology, School of Medicine, Washington University, St. Louis, MO, USA. ${ }^{3}$ Department of Psychiatry, School of Medicine, Washington University, St. Louis, MO, USA. ${ }^{4}$ Department of Neurology, Complejo Asistencial Universitario de Palencia, Palencia, Spain. ${ }^{5}$ Center for Applied Medical Research (CIMA) University of Navarra School of Medicine, Pamplona, Spain and Centro de Investigación Biomédica en Red Enfermedades Neurodegenerativas (CIBERNED), Madrid, Spain. ${ }^{6}$ Movement Disorders Unit, Department of Neurology, University Hospital Mutua de Terrassa, University of Barcelona, Terrassa, Barcelona, Spain. ${ }^{7}$ Department of Radiology, Anatomy \& Neurobiology, Program in Occupational Therapy, Program in Physical Therapy, Washington University, St. Louis, MO, USA. ${ }^{8}$ Hope Center Program on Protein Aggregation and Neurodegeneration, Washington University, St. Louis, MO, USA.

Received: 20 October 2015 Accepted: 14 April 2016 Published online: 19 April 2016

\section{References}

1. Dorsey ER, Constantinescu R, Thompson JP, Biglan KM, Holloway RG, Kieburtz K, Marshall FJ, Ravina BM, Schifitto G, Siderowf A, Tanner CM. Projected number of people with Parkinson disease in the most populous nations, 2005 through 2030. Neurology. 2007;68:384-6.

2. Sharma M, loannidis JPA, Aasly JO, Annesi G, Brice A, Van Broeckhoven C, Bertram L, Bozi M, Crosiers D, Clarke C, Facheris M, Farrer M, Garraux G, Gispert S, Auburger G, Vilariño-Güell C, Hadjigeorgiou GM, Hicks AA, Hattori N, Jeon B, Lesage S, Lill CM, Lin JJ, Lynch T, Lichtner P, Lang AE, Mok V, Jasinska-Myga B, Mellick GD, Morrison KE, et al. Large-scale replication and heterogeneity in Parkinson disease genetic loci. Neurology. 2012;79:659-67.

3. Valadas JS, Vos M, Verstreken P. Therapeutic strategies in Parkinson's disease: what we have learned from animal models. Ann N Y Acad Sci. 2015;1338:16-37.

4. Nalls MA, Pankratz N, Lill CM, Do CB, Hernandez DG, Saad M, DeStefano AL, Kara E, Bras J, Sharma M, Schulte C, Keller MF, Arepalli S, Letson C, Edsall C, Stefansson H, Liu X, Pliner H, Lee JH, Cheng R, International Parkinson's Disease Genomics C, Parkinson's Study Group Parkinson's Research: The Organized Genl, andMe, GenePd, NeuroGenetics Research C, Hussman Institute of Human G, Ashkenazi Jewish Dataset I, Cohorts for H, Aging Research in Genetic E, North American Brain Expression C, et al. Large-scale meta-analysis of genome-wide association data identifies six new risk loci for Parkinson's disease. Nat Genet. 2014:46:989-93.

5. Piccini P, Burn DJ, Ceravolo R, Maraganore D, Brooks DJ. The role of inheritance in sporadic Parkinson's disease: evidence from a longitudinal study of dopaminergic function in twins. Ann Neurol. 1999;45:577-82.

6. Thacker EL, Ascherio A. Familial aggregation of Parkinson's disease: a metaanalysis. Mov Disord. 2008;23:1174-83.

7. Do CB, Tung JY, Dorfman E, Kiefer AK, Drabant EM, Francke U, Mountain JL, Goldman SM, Tanner CM, Langston JW, Wojcicki A, Eriksson N. Web-based genome-wide association study identifies two novel loci and a substantial genetic component for parkinson's disease. PLoS Genet. 2011;7:e1002141.

8. Nalls MA, Plagnol V, Hernandez DG, Sharma M, Sheerin U-M, Saad M, Simón-Sánchez J, Schulte C, Lesage S, Sveinbjörnsdóttir S, Stefánsson K Martinez M, Hardy J, Heutink P, Brice A, Gasser T, Singleton AB, Wood NW. Imputation of sequence variants for identification of genetic risks for Parkinson's disease: a meta-analysis of genome-wide association studies. Lancet. 2011:377:641-9.

9. Pastor P, Ezquerra M, Muñoz E, Martí MJ, Blesa R, Tolosa E, Oliva R. Significant association between the tau gene AO/AO genotype and Parkinson's disease. Ann Neurol. 2000;47:242-5.

10. Lill CM, Roehr JT, McQueen MB, Kavvoura FK, Bagade S, Schjeide BMM, Schjeide LM, Meissner E, Zauft U, Allen NC, Liu T, Schilling M, Anderson KJ, Beecham G, Berg D, Biernacka JM, Brice A, DeStefano AL, Do CB, Eriksson N, Factor SA, Farrer MJ, Foroud T, Gasser T, Hamza T, Hardy JA, Heutink P, Hill-Burns EM, Klein C, Latourelle JC, et al. Comprehensive research 
synopsis and systematic meta-analyses in Parkinson's disease genetics: the PDgene database. PLoS Genet. 2012;8:e1002548.

11. Mata IF, Yearout D, Alvarez V, Coto E, de Mena L, Ribacoba R, LorenzoBetancor O, Samaranch L, Pastor P, Cervantes S, Infante J, Garcia-Gorostiaga I, Sierra M, Combarros O, Snapinn KW, Edwards KL, Zabetian CP. Replication of MAPT and SNCA, but not p ARK16-18, as susceptibility genes for Parkinson's disease. Mov Disord. 2011;26:819-23.

12. Keller MF, Saad M, Bras J, Bettella F, Nicolaou N, Simón-Sánchez J, Mittag F, Büchel F, Sharma M, Gibbs JR, Schulte C, Moskvina V, Durr A, Holmans P, Kilarski LL, Guerreiro R, Hernandez DG, Brice A, Ylikotila P, Stefansson H, Majamaa K, Morris HR, Williams N, Gasser T, Heutink P, Wood NW, Hardy J, Martinez M, Singleton AB, Nalls MA. Using genome-wide complex trait analysis to quantify "missing heritability" in Parkinson's disease. Hum Mol Genet. 2012;21:4996-5009.

13. Shannon B, Soto-Ortolaza A, Rayaprolu S, Cannon HD, Labbé C, Benitez BA, Choi J, Lynch T, Boczarska-Jedynak M, Opala G, Krygowska-Wajs A, Barcikowska M, Van Gerpen JA, Uitti RJ, Springer W, Cruchaga C, Wszolek ZK, Ross OA. Genetic variation of the retromer subunits VPS26A/B-VPS29 in Parkinson's disease. Neurobiol Aging. 2014;35:1958.

14. Benitez BA, Forero DA, Arboleda GH, Granados LA. Exploration of genetic susceptibility factors for Parkinson's disease in a South American sample. J Genet. 2010;89:229-32.

15. Davis AA, Andruska KM, Benitez BA, Racette BA, Perlmutter JS, Cruchaga C. Variants in GBA, SNCA, and MAPT influence Parkinson disease risk, age at onset, and progression. Neurobiol Aging. 2016;37:209.e1-7.

16. De A, Duque AF, Lopez JC, Benitez B, Hernandez H, Yunis JJ, Fernandez W, Arboleda H, Arboleda G. Analysis of the LRRK2 p.G2019S mutation in Colombian Parkinson's disease patients. Colombia Médica. 2015;46:117-21.

17. Ross OA, Soto-ortolaza Al, Heckman MG, Jan O, Abahuni N, Annesi G, Bacon JA, Bozi M, Brice A, Brighina L. Association of LRRK2 exonic variants with susceptibility to Parkinson's disease: a case-control study. Lancet Neurol. 2011;10:898-908.

18. Petrucci S, Consoli F, Valente EM. Parkinson disease genetics: a "continuum" from Mendelian to multifactorial inheritance. Curr Mol Med. 2014;14:1079-88.

19. Foo JN, Tan LC, Liany H, Koh TH, Irwan ID, Ng YY, Ahmad-Annuar A, Au WL, Aung T, Chan AYY, Chong SA, Chung SJ, Jung Y, Khor CC, Kim J, Lee J, Lim SY, Mok V, Prakash KM, Song K, Tai ES, Vithana EN, Wong TY, Tan EK, Liu J. Analysis of non-synonymous-coding variants of parkinson's disease-related pathogenic and susceptibility genes in East Asian populations. Hum Mol Genet. 2014:23:3891-7.

20. Spataro N, Calafell F, Cervera-Carles L, Casals F, Pagonabarraga J, Pascual-Sedano B, Campolongo A, Kulisevsky J, Lleó A, Navarro A, Clarimón J, Bosch E. Mendelian genes for Parkinson's disease contribute to the sporadic forms of the disease? Hum Mol Genet. 2014;24:2023-34.

21. Harms MB, Neumann D, Benitez BA, Cooper B, Carrell D, Racette BA, Perlmutter JS, Goate A, Cruchaga C. Parkinson disease is not associated with C9ORF72 repeat expansions. Neurobiol Aging. 2013;34:1519.e1-2.

22. Cruts M, Theuns J, Van Broeckhoven C. Locus-specific mutation databases for neurodegenerative brain diseases. Hum Mutat. 2012;33:1340-4.

23. Coppola G, Chinnathambi S, Lee J, Dombroski BA, Baker MC, Soto-ortolaza Al, Lee SE, Klein E, Huang AY, Sears R, Lane JR, Karydas AM, Kenet RO, Biernat J, Wang LS, Cotman CW, Decarli CS, Levey Al, Ringman JM, Mendez MF, Chui HC, Leber I, Brice A, Lupton MK, Preza E, Lovestone S, Powell J, Graff-radford N, Petersen RC, Boeve $\mathrm{BF}$, et al. Evidence for a role of the rare p.A152T variant in mapt in increasing the risk for FID-spectrum and Alzheimer's diseases. Hum Mol Genet. 2012;21:3500-12.

24. Wu MC, Lee S, Cai T, Li Y, Boehnke M, Lin X. Rare-variant association testing for sequencing data with the sequence kernel association test. Am J Hum Genet. 2011:89:82-93.

25. Clark LN, Ross BM, Wang Y, Mejia-Santana H, Harris J, Louis ED, Cote LJ, Andrews H, Fahn S, Waters C, Ford B, Frucht S, Ottman R, Marder K. Mutations in the glucocerebrosidase gene are associated with early-onset Parkinson disease. Neurology. 2007;69:1270-7.

26. Correia Guedes L, Ferreira JJ, Rosa MM, Coelho M, Bonifati V, Sampaio C. Worldwide frequency of G2019S LRRK2 mutation in Parkinson's disease: a systematic review. Parkinsonism Related Disord. 2010;16:237-42.

27. Ahn TB, Kim SY, Kim JY, Park SS, Lee DS, Min HJ, Kim YK, Kim SE, Kim JM, Kim HJ, Cho J, Jeon BS. a-Synuclein gene duplication is present in sporadic Parkinson disease. Neurology. 2008;70:43-9.

28. Anheim M, Elbaz A, Lesage S, Durr A, Condroyer C, Viallet F, Pollak P, Bonaïti $B$, Bonaïti-Pellié C, Brice A. Penetrance of Parkinson disease in glucocerebrosidase gene mutation carriers. Neurology. 2012;78:417-20.
29. Sidransky E, Nalls MA, Aasly JO, Aharon-Peretz J, Annesi G, Barbosa ER, Bar-Shira A, Berg D, Bras J, Brice A, Chen C-M, Clark LN, Condroyer C, De Marco E V, Dürr A, Eblan MJ, Fahn S, Farrer MJ, Fung H-C, Gan-Or Z, Gasser T, Gershoni-Baruch R, Giladi N, Griffith A, Gurevich T, Januario C, Kropp P, Lang AE, Lee-Chen G-J, Lesage S, et al. Multicenter analysis of glucocerebrosidase mutations in Parkinson's disease. N Engl J Med. 2009;361:1651-61.

30. Lwin A, Orvisky E, Goker-Alpan O, LaMarca ME, Sidransky E. Glucocerebrosidase mutations in subjects with parkinsonism. Mol Genet Metab. 2004;81:70-3.

31. Chabás A, Gort L, Díaz-Font A, Montfort M, Santamaría R, Cidrás M, Grinberg D, Vilageliu L. Perinatal lethal phenotype with generalized ichthyosis in a type 2 gaucher disease patient with the [L444P;E326K]/ P182L genotype: effect of the E326K change in neonatal and classic forms of the disease. Blood Cells Mol Dis. 2005;35:253-8.

32. Horowitz M, Pasmanik-Chor M, Ron I, Kolodny EH. The enigma of the E326K mutation in acid a-glucocerebrosidase. Mol Genet Metab. 2011;104:35-8.

33. Duran $R$, Mencacci NE, Angeli AV, Shoai M, Deas E, Houlden $H$, Mehta A, Hughes D, Cox TM, Deegan P, Schapira AH, Lees AJ, Limousin P, Jarman PR, Bhatia KP, Wood NW, Hardy J, Foltynie T. The glucocerobrosidase E326K variant predisposes to Parkinson's disease, but does not cause Gaucher's disease. Mov Disord. 2013:28:232-6.

34. Pankratz N, Beecham GW, Destefano AL, Dawson TM, Doheny KF, Factor SA, Hamza TH, Hung AY, Hyman BT, Ivinson AJ, Krainc D, Latourelle JC, Clark LN, Marder K, Martin ER, Mayeux R, Ross OA, Scherzer CR, Simon DK, Tanner C, Vance JM, Wszolek ZK, Zabetian CP, Myers RH, Payami H, Scott WK, Foroud T. Meta-analysis of Parkinson's disease: identification of a novel locus, RIT2. Ann Neurol. 2012;71:370-84

35. Benitez BA, Karch CM, Cai Y, Jin SC, Cooper B, Carrell D, Bertelsen S, Chibnik L, Schneider JA, Bennett DA, Fagan AM, Holtzman D, Morris JC, Goate AM, Cruchaga C. The PSEN1, p.E318G variant increases the risk of Alzheimer's disease in APOE-ع4 carriers. PLoS Genet. 2013;9: e1003685.

36. Spitz M, Pereira JS, Nicareta DH, Abreu Gde M, Bastos EF, Seixas TL, Pimentel MMG. Association of LRRK2 and GBA mutations in a Brazilian family with Parkinson's disease. Park Relat Disord. 2015;21:825-6.

37. Benitez BA, Cruchaga C. United States-Spain Parkinson's Disease Research Group. TREM2 and neurodegenerative disease. N Engl J Med. 2013;369: 1567-8.

38. Purcell S, Neale B, Todd-Brown K, Thomas L, Ferreira MAR, Bender D, Maller J, Sklar P, de Bakker PIW, Daly MJ, Sham PC. PLINK: A tool set for whole-genome association and population-based linkage analyses. Am J Hum Genet. 2007;81:559-75.

39. Jin S, Pastor P, Cooper B, Cervantes S, Benitez BA, Razquin C, Goate A, Cruchaga C. Pooled-DNA sequencing identifies novel causative variants in PSEN1, GRN and MAPT in a clinical early-onset and familial Alzheimer's disease Ibero-American cohort. Alzheimers Res Ther. 2012;4:34.

40. Jin SC, Benitez B a, Karch CM, Cooper B, Skorupa T, Carrell D, Norton JB, Hsu S, Harari O, Cai Y, Bertelsen S, Goate AM, Cruchaga C. Coding variants in TREM2 increase risk for Alzheimer's disease. Hum Mol Genet. 2014;23:5838-46.

41. Vallania FLM, Druley TE, Ramos E, Wang J, Borecki I, Province M, Mitra RD. High-throughput discovery of rare insertions and deletions in large cohorts. Genome Res. 2010:20:1711-8.

42. Benitez BA, Cooper B, Pastor P, Jin S-C, Lorenzo E, Cervantes S, Cruchaga C. TREM2 is associated with the risk of Alzheimer's disease in Spanish population. Neurobiol Aging. 2013;34:1711. e15-7.

43. Jin SC, Carrasquillo MM, Benitez BA, Skorupa T, Carrell D, Patel D, Lincoln S, Krishnan S, Kachadoorian M, Reitz C, Mayeux R, Wingo TS, Lah JJ, Levey Al, Murrell J, Hendrie H, Foroud T, Graff-Radford NR, Goate AM, Cruchaga C, Ertekin-Taner N. TREM2 is associated with increased risk for Alzheimer's disease in African Americans. Mol Neurodegener. 2015;10:19.

44. Benitez BA, Cairns NJ, Schmidt RE, Morris JC, Norton JB, Cruchaga C, Sands MS. Clinically early-stage CSPa mutation carrier exhibits remarkable terminal stage neuronal pathology with minimal evidence of synaptic loss. Acta Neuropathol Commun. 2015;3:73.

45. Gibbs JR, Singleton A. Application of genome-wide single nucleotide polymorphism typing: simple association and beyond. PLOS Genet. 2006:2:1511-7. 
46. Nalls MA, Bras J, Hernandez DG, Keller MF, Majounie E, Renton AE, Saad M, Jansen I, Guerreiro R, Lubbe S, Plagnol V, Gibbs JR, Schulte C, Pankratz N, Sutherland M, Bertram L, Lill CM, DeStefano AL, Faroud T, Eriksson N, Tung JY, Edsall C, Nichols N, Brooks J, Arepalli S, Pliner H, Letson C, Heutink P, Martinez M, Gasser T, et al. NeuroX, a fast and efficient genotyping platform for investigation of neurodegenerative diseases. Neurobiol Aging. 2015;36:1605. e7-e12.

Submit your next manuscript to BioMed Central and we will help you at every step:

- We accept pre-submission inquiries

- Our selector tool helps you to find the most relevant journal

- We provide round the clock customer support

- Convenient online submission

- Thorough peer review

- Inclusion in PubMed and all major indexing services

- Maximum visibility for your research

Submit your manuscript at www.biomedcentral.com/submit
Biomed Central 